\title{
Periferik fasiyal paralizi nedeni ile gabapentin kullanımında sinkinezi gelişimi
}

\author{
Lale Gündoğdu Çelebi' ${ }^{1}$ Zeynep Tanrıverdi ${ }^{1}$, Nevin Kuloğlu Pazarcı' ${ }^{1}$ Hülya Ertaşoğlu Toydemir ${ }^{1}$, Münevver Gökyiğit ${ }^{1}$
}

\begin{abstract}
ÖZET:
Periferik fasiyal paralizi nedeni ile gabapentin kullanımında sinkinezi gelişimi Amaç: Sinkinezi, fasiyal paralizi sonrası görülen en sık komplikasyonlardan biridir. Sinkinetik hareketler fasiyal sinirden innerve olan kasların anormal senkronizasyonu sonucu meydana gelir. Bu çalışmada fasiyal paralizi sonrasında Gabapentin kullanımının klinik sinkinezi gelişimine etkisinin değerlendirilmesi amaçlanmıştır.

Gereç ve Yöntem: Çalışmamıza 2008- 2010 yılları arasında Şişli Etfal Eğitim ve Araştırma Hastanesi Acil Nöroloji Polikliniği ve Nöroloji Polikliniğinde akut periferik fasiyal paralizi kliniği olan toplam 76 hasta alındı. Kırkiki hastaya standart kortikosteroid tedavisi ve periaurikuler ağrı nedeniyle 800 mg/ gün Gabapentin tedavisi başlandı. Kontrol grubu olan 34 hastaya, akut periferik fasiyal paralizide uygulanan standart kortikosteroid tedavisi başlandı. Tüm hastalarda fasiyal paralizinin ağırık derecesi House-Brackmann skalasına göre derecelendirildi. íki grup sinkinezi gelişimi açısından takibe alındı.

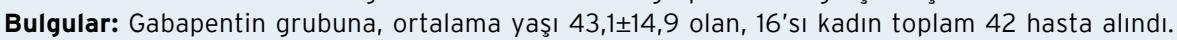

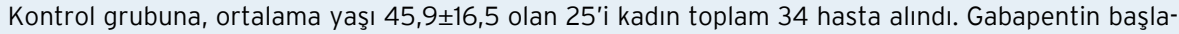
nan hasta grubundaki 7 hastada $(\% 16,7)$ ve kontrol grubundaki 13 hastada $(\% 38,2)$ sinkinezi geliştiği saptandı. íki grup arasında klinik olarak sinkinezi gelişimi açısından istatistiksel olarak anlamlı fark saptandı $(p<0,034)$. Gabapentin grubu ile kontrol grubu arasında klinik sinkinezi görülme zamanı arasında istatistiksel olarak anlamlı fark saptanmadı (p:0.816). Iki grubun takip süreleri arasında istatistiksel olarak anlamlı fark saptanmadı (P:0.303).

Sonuç: Sinkinezi, periferik fasiyal paralizinin bir komplikasyonudur ve önlenmesi ya da tedavi yöntemlerinin geliştirilmesi önemlidir. Bu çalışma Gabapentinin sinkinezi tedavisinde etkili olduğunu göstermektedir. Bizim sonuçlarımızın yapılacak çift kör plasebo kontrollü randomize planlanmış daha ileri çalışmalara temel oluşturacağına inanıyoruz.
\end{abstract}

Anahtar kelimeler: Periferik fasiyal paralizi, gabapentin, sinkinezi, fasiyal sinir

\section{ABSTRACT:}

Development of synkinesis as a sequela of peripheral facial paralysis treated with gabapentin

Objective: Facial synkinesis is one of the most complications of facial paralysis. Synkinetic movements are commonly occurs with the abnormal syncronization of the muscles that are innervated from the facial nerve. In this study, we aimed to evaluate the effect of gabapentin usage on the development of synkinesis after peripheral facial paralysis (PFP).

Material and Method: In our study, 76 patients who had acute peripheral facial paralysis between 2008-2010 in the Emergency Neurology Polyclinic and the Neurology Polyclinic of the Neurology Department of Şişli Etfal Research and Education Hospital were included. Forty-two patients were received standard corticosteroid therapy and $800 \mathrm{mg}$ per day gabapentin treatment because of periauricular pain. The control group of 34 patients were received the standard corticosteroid therapy of peripheral facial paralysis. All the patients were graded with the House-Brackmann scale. The groups were followed for the development of synkinesis.

Results: Mean \pm SD age of the patients who were received gabapenthin treatment was $43,1 \pm 14,9$ and 16 of 42 were female. Mean \pm SD age of the control group patients was $45,9 \pm 16,5$ and 25 of 34 were female. Synkinesis was developed in 7 patients $(\% 16,7)$ who were received gabapenthin treatment and 13 patients $(\% 38,2)$ in the control group. The development of clinical synkinesis was statistically different between two groups $(p<0,034)$. No significant difference was noted in the timing of synkinesis development and follow-up period between two groups ( $p: 0,816)(p: 0,303)$.

Conclusion: Synkinesis is an important complication of peripheral facial paralysis. Prevention and improvement of treatment modalities of PFP are important. This study shows that gabapentin is effective in the treatment of synkinesis. We conclude that our study will form a basis for advanced double blind randomized controlled trials.

Key words: Peripheral facial paralysis, gabapentin, synkinesis, facial nerve

Ş.E.E.A.H. Tıp Bülteni 2013;47(2):49-54
'Şişli Etfal Eğitim ve Araştırma Hastanesi, Nöroloji Kliniği, İstanbul-Türkiye

Yazışma Adresi / Address reprint requests to: Lale Gündoğdu Çelebi, Şişli Etfal Eğitim ve Araştırma Hastanesi, Nöroloji Kliniği, Halaskargazi Cd. Etfal Sk., 34377, istanbul-Türkiye

Telefon / Phone: +90-212-373-5000

Faks / Fax: +90-212-224-0772

E-posta / E-mail:

lale.gundogdu@sislietfal.gov.tr

Geliş tarihi / Date of receipt: 14 Ağustos 2012 / August 14, 2012

Kabul tarihi / Date of acceptance: 18 Haziran 2013 / June 18, 2013 


\section{GíRiş}

Fasiyal paralizi sonrası komplikasyon olarak görülen sinkinezi, bu sinirden innerve olan kasların anormal senkronizasyonudur. Sinkineziden sorumlu temel mekanizmalar; fasiyal sinir liflerinin anormal rejenerasyonu, sinir nukleusunun sinaptik reorganizasyonu, nöronal hipereksitabilite ve uyarıların aksonlar arasında periferal efaptik iletimidir (1-4).

Sinkinezinin birçok patterni bulunmaktadır. Ancak en sık görüleni, lateral oral kommissürün ve üst dudağın, göz kırpılması ya da kapatılması sırasında yukarı doğru hareketidir. Konuşurken ya da gülme sırasında göz kapağının kapanması şeklinde de olabilir. Bazen de otonomik sinkinezi şeklinde kendini gösterebilir (2).

A ̆̆ır fasiyal paralizili hastalarda sinkinezi gelişimi daha erken dönemde olmaktadır. Bazı gözlemciler, hastaların daha dikkatli değerlendirilmesi ile total periferal paralizili hastaların \%40 kadarında rejenerasyon tamamlandıktan sonra rezidüel parezi ve/ veya sinkinezi görülebileceğini belirtmiştir (1).

Bugün için en sık tedavi modaliteleri: Botulinum toksin tip A enjeksiyonları, fasiyal nöromüsküler eği- tim, biofeedback yöntemi, selektif nörolizis ya da miyektomi gibi cerrahi yöntemlerdir (5). Biz bu çalışmada, periaurikuler bölgede nöropatik ağrısı olan periferik fasiyal paralizili hastalarda erken dönemde başlanan Gabapentinin, sinkinezi gelişimine etkisini araştırmayı amaçladık.

\section{GEREÇ ve YÖNTEM}

Bu çalışmaya 2008-2010 yılları arasında Şişli Etfal Eğitim ve Araştırma Hastanesi Acil Nöroloji Polikliniği ve Nöroloji Polikliniğine akut gelişen periferik fasiyal paralizi ile ilk 5 günde başvuran hastalar alındı. Periaurikuler bölgede nöropatik ağrısı olan 42 hastaya 800 mg/gün Gabapentin tedavisi başlandı. Kontrol grubu olarak kortikosteroid kullanımı dışında ilaç kullanımı olmayan 34 hasta alındı.

Tüm hastaların kullandıkları ilaçlar, diabetes mellitus, hipertansiyon gibi kronik sistemik hastalıkları sorgulandı. Paralizinin başlangıç tarihi, klinik seyri, daha önce fasiyal paralizi geçirip geçirmediği, ailede fasiyal paralizi öyküsü, travma hikayesi, gebelik, enfeksiyon, cilt döküntüleri, başağrısı, baş dönmesi, işitme kaybı, tinnitus, geçirilmiş orta kulak iltihabı,

Tablo 1: House- Brackmann Fasiyal Paralizi Skalası

\begin{tabular}{|c|c|c|}
\hline Disfonksiyon derecesi & Paralizinin derecesi (Grade) & Özellikleri \\
\hline Normal & I & Bütün yüz bölgelerinde normal, simetrik fonksiyon \\
\hline Hafif Disfonksiyon & II & $\begin{array}{l}\text { Sadece dikkatli inceleme ile fark edilebilen hafif kas zayıflığı } \\
\text { Minimal efor ile gözünü tamamen kapatabilir } \\
\text { Maksimal efor ile gülümseme sırasında hafif asimetri } \\
\text { Güçlükle fark edilebilen sinkinezi bulunabilir } \\
\text { Kontraktür veya spazm yoktur }\end{array}$ \\
\hline Orta derecede disfonksiyon & III & $\begin{array}{l}\text { Belirgin kas zayıflığı } \\
\text { Kaşını kaldıramıyabilir } \\
\text { Maksimal efor ile gözünü tam kapatabilir } \\
\text { Maksimal efor ile ağız köşesinde asimetrik hareket vardır } \\
\text { Belirgin, ancak fonksiyon bozukluğu yaratmayan sinkinezi veya } \\
\text { kas spazmları bulunabilir }\end{array}$ \\
\hline Orta-Şiddetli disfonksiyon & IV & $\begin{array}{l}\text { Belirgin ve çehre bozukluğuna neden olan kas zayıflığı } \\
\text { Kaşını kaldıramaz } \\
\text { Maksimal efor ile gözünü tam kapatamaz } \\
\text { Maksimal efor ile ağız köşesinde asimetrk hareket vardır } \\
\text { Şiddetli sinkinezi veya kas spazmları bulunabilir }\end{array}$ \\
\hline Şiddetli disfonksiyon & V & $\begin{array}{l}\text { Zorlukla fark edilebilen hareket } \\
\text { Göz kapağında çok zayıf hareket vardır, ancak gözünü kapatamaz } \\
\text { Ağız köşesinde çok zayıf hareket vardır } \\
\text { Sinkinezi, kontraktür veya spazm yoktur }\end{array}$ \\
\hline Komplet paralizi & VI & $\begin{array}{l}\text { Yüzde hiç hareket yoktur ve istirahat halinde tonus kaybolmuştur } \\
\text { Sinkinezi, kontraktür veya spazm yoktur. }\end{array}$ \\
\hline
\end{tabular}


tat alamama, ağızda kuruluk olup olmadığı sorgulandı ve bulgular kaydedildi. Diğer kraniyal sinirlere ait patoloji ve parezi olup olmamasına muayenede özellikle dikkat edildi. Hastaların KBB (kulak burun boğaz) muayeneleri yaptırıldı.

Daha önceye ait periferik fasiyal paralizi öyküsü, fasiyal diplejisi, ilaç kullanımı açısından kontrendikasyonu olan, akut otitis media sonrası fasiyal paralizi geliştiği saptanan ve 18 yaş altındaki hastalar çalışmadan dışlandı. Şişli Etfal Eğitim ve Araştırma Hastanesi etik kurulu onayı alındı. Çalışma ile ilgili tüm hastalar bilgilendirilerek onam formları dolduruldu.

Hastalar ilk başvuru anında House- Brackmann fasiyal paralizi skalasına göre değerlendirildi (Tablo 1). Hastalara ilk 5 gün içinde $1 \mathrm{mg} / \mathrm{kg} /$ gün prednizon eş değeri metilprednizolon, topikal gözyaşı damlaları reçete edilerek standart tedavi protokolü uygulandı ve 42 hastaya ek olarak periaurikuler nöropatik ağrı nedeniyle 800 mg/gün Gabapentin başlandı ve 1,5 ay süre ile kullanıldı.

Olguların tamamına periferik fasiyal paralizinin başlangıcından sonraki 5 ile 10. günleri arasında gün aşırı 3 kez nasalis kasından kayıt, mastoid fossa uyarısı ile Elektronöronografi (ENOG) incelemesi yapıldı.

Elektrofizyolojik testler, Nıhon KOHDEN Corporation EP/ EMG measuring sistem model/ meb $9104 \mathrm{~K}$ power Input 150 VD/ SN 00019 ve Medelec Saphire 4E EMG makineleri kullanılarak gerçekleştirildi. Elektrofizyolojik olarak direk yanıt (DY) kaydı yapıldı.

DY yanıt kaydı için, yüzey elektrodları bilateral olarak nasalis kasları üzerine yerleştirildi. Toprak elektrodu ise el bileğine yerleştirildi. Fasiyal sinirler stilomastoid fossa üzerinden önce asemptomatik sonra semptomatik taraftan olmak üzere uyarıldı. Stimülasyonun yapıldığı tarafa konan elektrod aktif elektrod olarak belirlendi. Semptomatik tarafta ortaya çıkan Bileşik Kas Aksiyon Potansiyeli (BKAP) amplitüdünün asemptomatik tarafta ortaya çıkan BKAP amplitüdüne oranı hesaplandı (DY oranı). Her hasta için minimum DY oranını sağlayan kayıtlar değerlendirmeye alındı.

Hastaların aylık nörolojik değerlendirilmeleri yapıldı ve bulguları kaydedildi. Hastalarda kontroller sırasında otonomik sinkinezi açısından timsah gözyaşı sendromu varlığı sorgulandı. Muayene sırasında, sıklıkla motor sinkinezi ile ilişkili olduğu bildirilen
Orbikularis oculi ile ağız elevatör kaslarında eş zamanlı kasılma olup olmadığının tespitine özen gösterildi. Ayrıca muayene sırasında kontraktür gelişip gelişmediğine dikkat edildi.

Tüm hastalar en az 6 ay boyunca sinkinezi gelişimi açısından izlendi. Klinik kontroller sırasında sinkinezi saptanan olguların takibi sonlandırıldı. Periferik fasiyal paralizinin başlangıcından itibaren 6 ayı aşan hastalar takiplere geldiği sürece izlenmeye devam edildi.

İstatistik değerlendirme için SPSS (Statistical Package for Social Sciences ) Windows 11 paket pogramı kullanıldı. İstatistiksel olarak anlamlılık $p<0,05$ olarak kabul edildi.

\section{BULGULAR}

Çalışmamıza akut periferik fasiyal paralizinin ilk 5 gününde periaurikuler ağrı nedeniyle 800 mg/gün Gabapentin başlanmış olan 16'sı kadın 42 hasta alındı. Hastaların yaş aralıkları 19-75 arasında (ortalama $43,1 \pm 14,9$ ) idi. Klinik ağılık dereceleri House-Brackmann skalasına göre evre 2 ile 4 arasındaydı. Kontrol grubu olarak alınan 25'i kadın 34 hastanın yaş aralık-

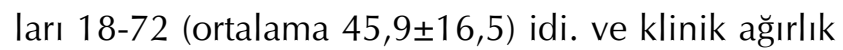
dereceleri evre 3-4 idi.

Gabapentin grubu ve kontrol grubundaki tüm

Tablo 2: Tüm hastalarda sinkinezi görülme oranı

\begin{tabular}{lcc}
\hline $\begin{array}{l}\text { Total Hasta } \\
\text { Sayısı }\end{array}$ & $\begin{array}{l}\text { Sinkinezi (+) } \\
\text { Hasta Sayısı }\end{array}$ & $\begin{array}{c}\text { Sinkinezi (-) } \\
\text { Hasta Sayısı }\end{array}$ \\
\hline 76 & $20(\% 26,3)$ & $56(\% 73,7)$
\end{tabular}

Tablo 3: Gabapentin grubu ve kontrol grubunda sinkinezi gelişme oranı

\begin{tabular}{lcc}
\hline & Sinkinezi (+) & Sinkinezi(-) \\
\hline $\begin{array}{l}\text { Gabapentin grubu } \\
\text { (42 hasta) }\end{array}$ & $7(\% 16,7)$ & $35(\% 83,3)$ \\
$\begin{array}{l}\text { Kontrol grubu } \\
\text { (34 hasta) }\end{array}$ & $13(\% 38,2)$ & $21(\% 61,8)$ \\
\end{tabular}

Tablo 4: Gabapentin grubu ile kontrol grubunun klinik sinkinezi görülme zamanları

\begin{tabular}{lccc}
\hline & $\begin{array}{c}\text { Klinik sinkinezi } \\
\text { görülme zamanı }\end{array}$ & Ort \pm SD & P \\
\hline Gabapentin Grubu & $3-9$ ay & $5,3 \pm 1,9$ & 0.816 \\
Kontrol Grubu & $4-13$ ay & $6,7 \pm 3,2$ & 0.816
\end{tabular}


Tablo 5: DY Oranı \%40'ın altında ve üzerinde olan hastalarda sinkinezi gelişimi

\begin{tabular}{llccc}
\hline & & Sinkinezi (+) & Sinkinezi (-) & Total \\
\hline DY Oranı < \% 40 & Gabapentin grubu & 3 & 8 & 11 \\
& Kontrol grubu & 12 & 6 & 18 \\
DY Oranı $>\% 40$ & Gabapentin grubu & 4 & 27 & 31 \\
& Kontrol grubu & 1 & 15 & 16
\end{tabular}

hastalar değerlendirildiğinde; toplam 76 hastanın 20 'sinde (\%26,3) sinkinezi geliştiği, 56'sında (\%73,7) gelişmediği görüldü (Tablo 2).

Gabapentin grubundaki 42 hastanın $7^{\prime}$ sinde $(\% 16,7)$, kontrol grubundaki 34 hastanın 13'ünde $(\% 38,2)$ sinkinezi geliştiği saptandı (Tablo 3). Sinkinezi gelişmiş olan tüm hastalar House- Brackmann fasiyal paralizi skalasına göre evre 3-4 idi. Gabapentin grubu ve kontrol grubundaki hastalar klinik sinkinezi gelişimi açısından karşılaştırıldığında aralarında istatistiksel olarak anlamlı fark olduğu görüldü $(p<0,034)$. Gabapentin kullanan hastalarda sinkinezi

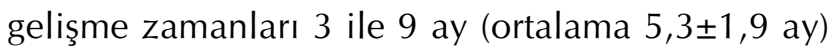
arasındaydı. Kontrol grubundaki hastalarda sinkinezi gelişme zamanı 4-13 ay ( ortalama $6,7 \pm 3,2$ ay ) arasında idi (Tablo 4). Hastaların takip süresi Gabapentin grubunda $3-15$ ay idi ( ortalama $7 \pm 3,1$ ), kontrol grubunda ise $4-13$ ay ( ortalama $7.4 \pm 3,6$ ) idi.

Gabapentin grubu ile kontrol grubu arasında klinik sinkinezi görülme zamanı ve takip süreleri açısından anlamlı fark yoktu ( $p=0.816)(P=0.303)$ (Tablo 4). Gabapentin kullanan ve sinkinezi gelişmeyen hastaların takip süreleri 3-15 ay (ortalama 7,3 $\pm 3,2$ ) idi. Hastalarda DY oranlarına göre sinkinezi gelişimi değerlendirildiğinde; Gabapentin kullanan grupta DY oranı \%40'ın altında olan 11 hastanın 3'ünde $(\% 27,3)$, kontrol grubunda ise DY oranı $\% 40$ 'ın altında olan 18 hastanın 12'sinde $(\% 66,7)$ sinkinezi görüldü. Gabapentin grubu ve kontrol grubunda DY oranı $\%$ \% 'ın altında olan hastalarda sinkinezi gelişimi açısından istatistiksel olarak anlamlı fark görüldü $(p<0.039)$ (Tablo 5).

\section{TARTIŞMA VE SONUÇ}

Literatür incelendiğinde, fasiyal paralizi sonrası gelişen sinkinezi insidansı farklı çalışmalarda \%9,155 arasında oldukça değişken oranlarda görülmüştür $(3,9,10)$. Elektrofizyolojik bulgulara göre Kimura ve arkadaşları sinkinetik hareketlerin, fasiyal sinir dallarının inerve ettikleri kaslara doğru ayrılmaya başladıkları yerden önce rejenere olan vakaların neredeyse tamamında ortaya çıktığını bildirmektedir $(3,11)$.

Fasiyal sinir dallarından birinden diğerine patolojik impuls iletiminin varlığını göstermek için kullanılan elektrofizyolojik yöntemler: 1) Lateral yayılım yanıtı: fasiyal sinirin bir dalı uyarıldığında başka bir dal tarafından innerve olan bir kasta oluşan geç yanıtın kaydı, 2) Supraorbital sinir refleksinin aşağıdaki yüz kaslarına doğru sinkinetik yayılımının kaydıdır. Akut fasiyal paralizide kullanılan diğer bir elektrofizyolojik yöntem ise ENOG 'tur. Bu yöntemle etkilenen tarafla sağlam taraf arasındaki bileşik kas aksiyon potansiyellerinin (BKAP) amplitüdleri karşılaştırılmaktadır. ENOG fasiyal paralizide sinir hasarının ağırlığını göstermede en erken kullanılabilecek testlerden biridir ve prognostik değeri vardır (3). Çalışmamızda tüm hastalar ENOG testi ile değerlendirilmiştir.

Fasiyal paralizi sonrası sinkinezi gelişiminin önlenmesi için çeşitli tedavi yöntemleri denenmiştir:

Nakamura ve arkadaşları, fasiyal paralizi sonrasında gelişen sinkinezinin önlenmesi için biyofeedback rehabilitasyonun etkinliğini araştırmışlardır. Biofeedback yöntemininin sinkinezi gelişimini önleme açısından etkin olduğunu vurgulamışlardır (12).

Gaye ve arkadaşları nöromüsküler fasiyal eğitim ile EMG kombinasyonunun fasiyal paralizi rehabilitasyonunda ve sinkinezinin azaltılmasında etkili olduğunu saptamışlardır (13).

Postparetik fasiyal sinkinezi tedavisinde selektif miyektomi de etkili bir yöntemdir. Düşük rekürrens oranına sahiptir ancak bu prosedür sonrasında hematom, lenfadenom ve ekimoz izlenebilir (14).

Selektif nörolizis sinkineziyi geçici olarak hafifletebilir, ancak sinkinezi sıklıkla tekrarlar ve tekrarladığında semptomları öncekinden daha şiddetli olabilmektedir. Botulinum toksini alanındaki gelişmeler ile 
birlikte bu cerrahi yöntemler de artık sık uygulanmamaktadır (5).

Botulinum toksin- A enjeksiyonu sinkineziyi azaltmaktadır ancak pitoz, göz kuruluğu ve kas güçsüzlüğüne bağlı olarak çiğneme sorunları oluşabilir $(5,15)$. Ayrıca etkisi geçici olduğundan tekrarlayıcı enjeksiyonlar gerekli olabilir.

Gabapentin Fabio ve arkadaşları tarafından hemifasiyal spazmlı 5 hastanın tedavisinde uygulanmıştır. Hızlı ve net bir iyileşme gözlendiği için Gabapentinin hemifasyal spazmın tedavisinde etkili olabileceğini belirtmişlerdir (7). Daniele ve arkadaşları hemifasyal spazmı azaltmada Gabapentini efektif ve güvenli bulmuşlar, bu bilgiyi desteklemek için daha uzun süreli takiplere ve geniş hasta grupları ile yapılacak kontrollü çalışmalara ihtiyaç olduğunu belirtmişlerdir (8). Patel ve arkadaşları Gabapentini hemifasiyal spazmlı bir hastanın tedavisinde kullanmışlar ve Gabapentinin kullanılan standart tedavi yöntemlerine alternatif olabileceğini belirtmişlerdir (16).

Gabapentin GABA analoğu olan yeni kuşak antikonvulsan ilaçtır, Etkisi voltaja bağımlı Ca kanallarının blokajı ile oluşur. Gabapentinin, spinal kord arka boynuzunda hem presinaptik glutamat salınımını azalttığı hem de postsinaptik $\mathrm{Ca}^{++}$kanallarının alfa- 2 delta alt ünitesine bağlanarak glutamat transmisyonuna bağlı santral sensitizasyonu önlediği gösterilmiştir. Bu etkileri nedeni ile günümüzde nöropatik ağrı tedavisinde de kullanılmaktadır (6).

Literatürde Gabapentinin hemifasyal spazm ve distoni tedavilerinde yaygın kullanımı olmasına rağmen postparalitik fasiyal sinkinezi tedavisi veya önlenmesine yönelik bir veriye rastlamadık. Gabapentinin nöronal hipereksitabiliteyi azaltması nedeniyle, sinkinezi gelişimini de engelleyebileceği öngörüsüyle çalışmamızı planladık.

Sonuçlarımız incelendiğinde, Gabapentin gru- bunda sinkinezi gelişimi istatistiksel olarak anlamlı oranda azdı (Tablo 3).

Yamamoto ve arkadaşları sinkinezinin en çok fasiyal paralizinin ortalama 5,9-9,8 ayları arasında ortaya çıktığını göstermişlerdir $(3,10)$. Bizim çalışmamızda Gabapentin kullanan grupta sinkinezi gelişimi 3-9 ay arasında, kontrol grubunda ise 4-13 aylar arasında idi. Çelik ve arkadaşları periferik fasiyal paralizi sonrası DY oranı \%40'ın altında olan hastaların yaklaşık \%78'inde klinik sinkinezi görüldügünü bildirmiştir. DY oranları \%40'ın üzerinde olan hastalarda sinkinezi gelişme olasılığının oldukça düşük olduğunu, sinkinezi gelişiminin iyileşmeyi takiben çok uzun bir süre sonra meydana geldiğini ve şiddetli aksonal kayıpta ise sinkinezinin genellikle fasiyal paraliziyi takiben 4-8 ay içerisinde geliştiğini belirtmişlerdir (3).

Biz çalışmamızda Gabapentin alan ve DY oranı $\% 40$ 'ın altında olan hastalarda sinkinezi gelişimi $\% 27$ oranında idi. Kontrol grubunda ise bu oran $\% 66,6$ idi. Ayrıca Gabapentinin DY oranı \%40'ın altında olan hastalarda sinkinezi gelişimini anlamlı olarak azalttığını saptandık $(p<0,039)$. Bu nedenle Gabapentinin sinkinezi tedavisinde etkili olabileceği düşüncesindeyiz.

Bulgularımız literatürle karşılaştırıldığında, Gabapentin kullanan grupta sinkinezinin daha nadir görüldüğü ancak sinkinezi gelişmiş ise bulguların daha erken ortaya çıktığı görüldü. Bu durumu hastaların fasial paralizi evresinin daha ileri ve ağır olmasına bağlıyoruz.

Sonuç olarak; sinkinezi, periferik fasiyal paralizinin oldukça önemli bir komplikasyonudur ve önlenmesi ya da tedavi yöntemlerinin geliştirilmesi önemlidir. Bizim sonuçlarımızın yapılacak çift kör plasebo kontrollü randomize planlanmış daha ileri çalışmalara temel oluşturacağına inanıyoruz.

\section{KAYNAKLAR}

1. Roger L. Crumley, San Francisco, California: Mechanızms of synkınesis. The Laryngoscope 1979; 89: 1847-1854.

2. May M: Facial nerve paralysis. in Paparella MM, Shumrick DA. (eds): Otolaryngology, Philedelphia, WB Sauders Co., 1991; p.1097-1136.

3. Münevver Çelik, Hulki Forta, Çetin Vural: The Development of Synkinesis after Facial Nerve Paralysis. European Neurology 2000; 43: 147-151.

4. C. John Moran, J. Gail Neely. Patterns of Facial Nerve Synkinesis. Laryngoscope December 1996; 106: 1491-1496.

5. Husseman J, Mehta RP. Management of synkinesis. Facial Plast Surg. May 2008; 24 (2): 242-249.

6. Keskinbora K, Pekel AF, Aydınlı I. Periferik Nöropatik Ağrının Kontrolünde Gabapentin ve Amitriptilinin Etkinliğinin Karşılaştırılması. A ğrı 2006; 18(2): 34-40. 
7. Fabio Bandini, Luca Mazzella. Gabapentin as treatment for Hemifacial spasm. European Neurology 1999; 42(1): 49-51.

8. Daniele O, Caravaglios G, Marchini C, Mucchiut M, Capus L, Natale E. Gabapentin in the treatment of hemifacial spasm. Acta Neurol Scand 2001; 104: 110-112.

9. Maeyama H, Aoyagi M, Tojima H, Inamura H, Kohsyu H, Koike Y. Electrophysiological study on the pathology of synkinesis after facial nerve paralysis. Acta Otolaryngol (Stockh) 1994; suppl 551: 161-164.

10. Yamamoto $E$, Nishimura $H$, Hirono Y. Occurrence of sequelae in Bell's palsy. Acta Otolaryngol (Stockh) 1988; suppl 446: 93-96.

11. Kimura J. Rodnitzky RL, Okawara SH. Electrophysiologic analysis of aberrant regeneration after facial nerve paralysis. Neurology 1975;25: 989-993.
12. Katsuhıko Nakamura, Naokı Toda, et al. Biofeedback rehabilitation for prevention of synkinesis after facial palsy. Otolaryngol Head Neck Surg 2003; 128: 539-543.

13. Gaye W. Cronın, MHE, OTR, and Ronald Leif Steenerson, MD. The effectiveness of neuromuscular facial retraining with electromyography in facial paralysis rehabilitation. Otolaryngol Head Neck Surg. 2003; 128: 534-538.

14. Jorge Orlando Guerrissi. Selective Myectomy for Postparetic Facial Synkinesis. Plastic and Reconstructive Surgery March 1999; 87(3): p. 459-466.

15. Josep Vals-Sole, Jordi Montero. Movement Disorders in Patient With Peripheral Facial Palsy. Movement Disorders 2003: 18(12): p.1424-1435.

16. Patel J, Naritoku DK. Gabapentin for the treatment of hemifacial spasm. Clin Neuropharmacol 1996 Apr; 19(2): 185-188. 